\title{
COMPARATIVE STUDY BETWEEN BALLOON ANGIOPLASTY AND BYPASS SURGERY IN LONG SUPERFICIAL FEMORAL ARTERY LESIONS
}

\author{
By
Mohamed Hamdy Hassan, Hany Abd El-Moamen Abd El-Fatah and Omar Mokhtar Ibrahim

Department of Vascular Surgery, Faculty of Medicine, Al-Azhar University, Cairo, Egypt

Corresponding author: Mohamed Hamdy Hassan,

Phone: (+2)01152235812, E-mail: hamdyvascular@gmail.com

\begin{abstract}
Background: Critical limb ischemia is the most advanced stage of peripheral arterial occlusive disease. The prognosis is poor, with amputation rates up to $30 \%$ and mortality up to $25 \%$ after 1 year.

Objective: To compare using of balloon angioplasty versus bypass surgery in management of long superficial femoral artery (SFA) lesions.

Patients and methods: A prospective comparative study conducted at the Vascular Surgery Department at Al-Azhar University Hospitals starting from November 2019 to November 2020. The study included (30) patients ( 15 patients were treated by angioplasty and 15 patients were treated by autogenous femoro popliteal bypass) suffering from long SFA lesions.

Results: No statistical difference was found regarding age and sex distribution and associated comorbidities. Technical success rate after endovascular intervention (group A) reached $93.3 \%$ compared to $86.7 \%$ in femoropopliteal bypass (group B). Procedure duration was $1.1 \pm 0.85$ compared to $2.8 \pm 1.7$ in Group B. This was statistically lower in endovascular group $(\mathrm{P}=0.032)$. Mean hospital stay was $0.6 \pm 0.35$ compared to 3.1 \pm 2.6 in Group B. This was statistically lower in endovascular group $(\mathrm{P}=0.013)$. We achieved a limb salvage rate of $14(93.3 \%)$ in group A and 13 patients $(86.7 \%)$ for group B and a major amputation rate of $6.7 \%$ (1 patients) in group A and 13.3\% (2 patients) in group B over 1-year follow-up period. No difference was found between both interventions.
\end{abstract}

Patency rate at 12 months was higher in group B than in group A (66.7\% vs. 46.7\%). $\mathrm{P}=0.27$. Postoperative improvement of ankle brachial pressure index (ABPI) was statistically non-different $(\mathrm{P}=0.07$, 0.89). Superficial infection, Deep infection and Seroma were all confined to bypass group. Other complications were not statistically different in both groups. There was no significant difference in the mortality rate which was $6.7 \%$ and $13.3 \%$ in group A and B respectively.

Conclusion: Both balloon angioplasty and bypass surgery were safe and effective method for treatment of long SFA lesions. Bypass group showed better patency rates at final follow up.

Keywords: Angioplasty; vascular bypass; femoral artery.

\section{INTRODUCTION}

The incidence of PAD is increasing worldwide due to an overall increase in diabetes, obesity, and other cardiovascular disorders. Importantly, the incidence of
PAD will continue to increase, as the condition has historically been diagnosed in elderly populations, which are also rising worldwide (Pattillo, et al., 2011). Critical limb ischemia is the most 
advanced stage of peripheral arterial occlusive disease. The prognosis is poor, with amputation rates up to $30 \%$ and mortality up to $25 \%$ after 1 year (Norgren, et al., 2017).

Percutaneous transluminal angioplasty (PTA) and surgical bypass are both accepted treatments for claudication due to superficial femoral artery (SFA) occlusive disease (Siracuse, et al., 2012).

Treatment of CLI aims at wound healing, improvement in quality of life, limb loss prevention, and prolonged survival. Current strategies propose endovascular or open revascularization (Bosanquet et al., 2016).

Surgical bypass for the primary treatment of claudication showed improved freedom from restenosis and symptom relief despite treatment of more extensive disease, but was associated with increased mean length of stay and wound infection. Statins improved freedom from restenosis and symptom recurrence overall (Siracuse et al., 2012).

The obtained findings of Papoian et al. (2018) demonstrated encouraging immediate and remote results of the interventions performed, thus making it possible to recommend the use of angioplasty and stenting for long occlusion of the SFA, yielding satisfactory results in the majority of cases, both immediately after the operation and in the remote period.

Open surgical techniques despite the advances made in the field of endovascular technology, open surgery still remains the gold standard for type C and D lesions (Karkos et al., 2017).
This study aimed to find the difference between endovascular and surgical bypass in treating long SFA lesions.

\section{PATIENTS AND METHODS}

Study design:This comparative study was conducted at the Vascular Surgery Department at Al-Azhar university hospitals starting from November 2019 to November 2020. The study included 30 patients (15 patients were treated by angioplasty $\& 15$ patients were treated by femoro popliteal bypass) suffering from long SFA lesions.

\section{Inclusion criteria:}

Symptomatic, atherosclerotic long SFA lesion (TASC B \& C), critical lower limb ischemia (persistent rest pain of more than two weeks duration or ulcers or tissue loss or gangrene of one or more toes or ankle brachial pressure index $(\mathrm{ABPI})<0.4$, or peak systolic velocity (PSV)> $300 \mathrm{~cm}$ per $\mathrm{sec})$, Informed consent was provided.

\section{Exclusion criteria:}

Acute limb ischemia, short SFA lesion (TASC A), total SFA long occlusion (TASC D), patients with poor run-off, Previous endovascular or surgical treatment of the affected side, patients unfit for intervention, and severe renal failure.

\section{Patient evaluation:}

After informed written consents and ethical committee approval had been obtained, patients were subjected to clinical evaluation. Investigations included:

1. Laboratory (CBC, blood sugar level, kidney functions, liver functions, 
coagulation profile, lipid profile and hepatitis markers).

2. Radiological: A. plain X ray foot, and B. Duplex ultrasound to evaluate the arterial system prior to CT angiography.

Statistical analysis was done by the statistical package for the social sciences (SPSS) v. 25. Description of quantitative variables as mean, $\mathrm{SD}$ and range.
Description of qualitative variables as number and percentage. Chi-square test was used to compare qualitative variables.

Two sample t-test was used to compare quantitative variables between independent groups in parametric data. Pvalue $<0.05$ was considered significant.

\section{RESULTS}

No statistical difference was found regarding age, sex distribution and associated comorbidities (Table 1).

Table (1): Distribution of the studied patients regarding their sex

\begin{tabular}{|c|c|c|c|c|c|}
\hline \multirow{2}{*}{$\begin{array}{ll}\text { Parameter } & \text { Group } \\
\end{array}$} & \multicolumn{2}{|c|}{ Group A. $N=15$} & \multicolumn{2}{|c|}{ Group B. $N=15$} & \multirow{2}{*}{$\mathrm{P}$} \\
\hline & $\mathrm{N}$ & $(\%)$ & $\mathrm{N}$ & $(\%)$ & \\
\hline Male & 9 & $60 \%$ & 8 & $53 \%$ & \multirow{2}{*}{$>0.05$} \\
\hline Female & 6 & $40 \%$ & 7 & $47 \%$ & \\
\hline $\begin{array}{l}\text { TASC II category } \\
\text { B }\end{array}$ & 11 & $73.3 \%$ & 13 & $86.7 \%$ & \multirow[t]{2}{*}{$>0.05$} \\
\hline $\mathrm{C}$ & 4 & $26.7 \%$ & 2 & $13.3 \%$ & \\
\hline IHD & \multicolumn{2}{|c|}{4} & \multicolumn{2}{|c|}{8} & $>0.05$ \\
\hline C.V.S. & \multicolumn{2}{|c|}{2} & \multicolumn{2}{|c|}{2} & $>0.05$ \\
\hline D.M. & \multicolumn{2}{|c|}{10} & \multicolumn{2}{|c|}{15} & 0.021 \\
\hline Smoking & \multicolumn{2}{|c|}{9} & \multicolumn{2}{|c|}{10} & $>0.05$ \\
\hline Hypertension & \multicolumn{2}{|c|}{8} & \multicolumn{2}{|c|}{11} & $>0.05$ \\
\hline Dyslipidemia & \multicolumn{2}{|c|}{12} & \multicolumn{2}{|c|}{11} & $>0.05$ \\
\hline Age Mean \pm S.D) & \multicolumn{2}{|c|}{$60.7 \pm 12.35$} & \multicolumn{2}{|c|}{$66.2 \pm 11.24$} & $>0.05$ \\
\hline
\end{tabular}

Symptoms and signs of patients included in this study included rest pain, ischemic ulcers, gangrene of toe, heel or forefoot as shown below. Rest pain was found in 9patients in group $\mathrm{A}$ and 11 in group B. Ischemic ulcer was found in 6 patients in group $\mathrm{A}$ and 5 in group $\mathrm{B}$ (Figure 1). 


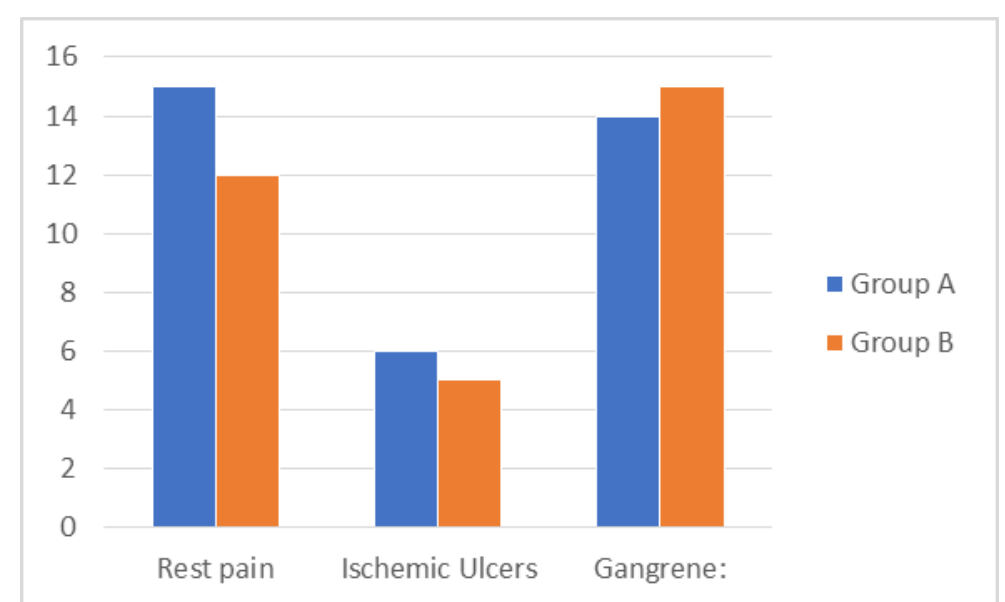

Figure (1): Symptoms and signs of patients included in this study

A total number of 30 procedures were performed for 30 patients (all were unilateral) for treatment of critical limp ischemia due to long SFA lesion. In endovascular group, lesions were crossed intraluminal in $14(93.33 \%)$ patients and subintimal in $1(6.67 \%)$ patient. TASC categories were shown in Table (1).

Mean operation time was calculated for each procedure and exact numbers are shown in the table below. In Group A, procedure duration was $1.1 \pm 0.85$ compared to $2.8 \pm 1.7$ in Group B. This was statistically lower in endovascular group $(\mathrm{P}=0.032)$.

Mean hospital stay was calculated for each procedure and exact numbers are shown in the table below. In Group A, mean hospital stay was $0.6 \pm 0.35$ compared to $3.1 \pm 2.6$ in Group B. This was statistically lower in endovascular group $(\mathrm{P}=0.013)$.

Among our 30 patients, technical success rate after endovascular intervention (group A) reached 93.3\% compared to $86.7 \%$ in femoropopliteal bypass (group B).

We achieved a limb salvage rate of 14 $(93.3 \%)$ in group $\mathrm{A}$ and 13 patients $(86.7 \%)$ for group $B$ and a major amputation rate of $6.7 \%$ ( 1 patients) in group A and $13.3 \%$ (2 patients) in group B over 1-year follow-up period. No difference was found between both interventions (Table 2).

Table(2): Limb salvage

\begin{tabular}{|c|c|c|c|c|}
\hline \multirow{2}{*}{$\begin{array}{l}\text { Period } \\
\text { (months) }\end{array}$} & \multicolumn{2}{|c|}{ Group A } & \multicolumn{2}{c|}{ Group B } \\
\cline { 2 - 5 } & N. of limp lost & Salvage & N. of limp lost & Salvage \\
\hline 1 & 0 & 15 & 0 & 15 \\
\hline 3 & 0 & 15 & 1 & 14 \\
\hline 6 & 1 & 14 & 2 & 13 \\
\hline 12 & 1 & 14 & 2 & 13 \\
\hline Total N. of limp lost & $1(6.7 \%)$ & $14(93.3 \%)$ & $2(13.3 \%)$ & $13(86.7 \%)$ \\
\hline p-value & \multicolumn{3}{|c|}{$>0.05$} \\
\hline
\end{tabular}

Patency rate at 12 months was higher in group B than in group A $(66.7 \%$ vs. $46.7 \%)$. The chi-square statistic was
1.2217. The p-value was 0.269023 . The result was not significant (Figure (2). 


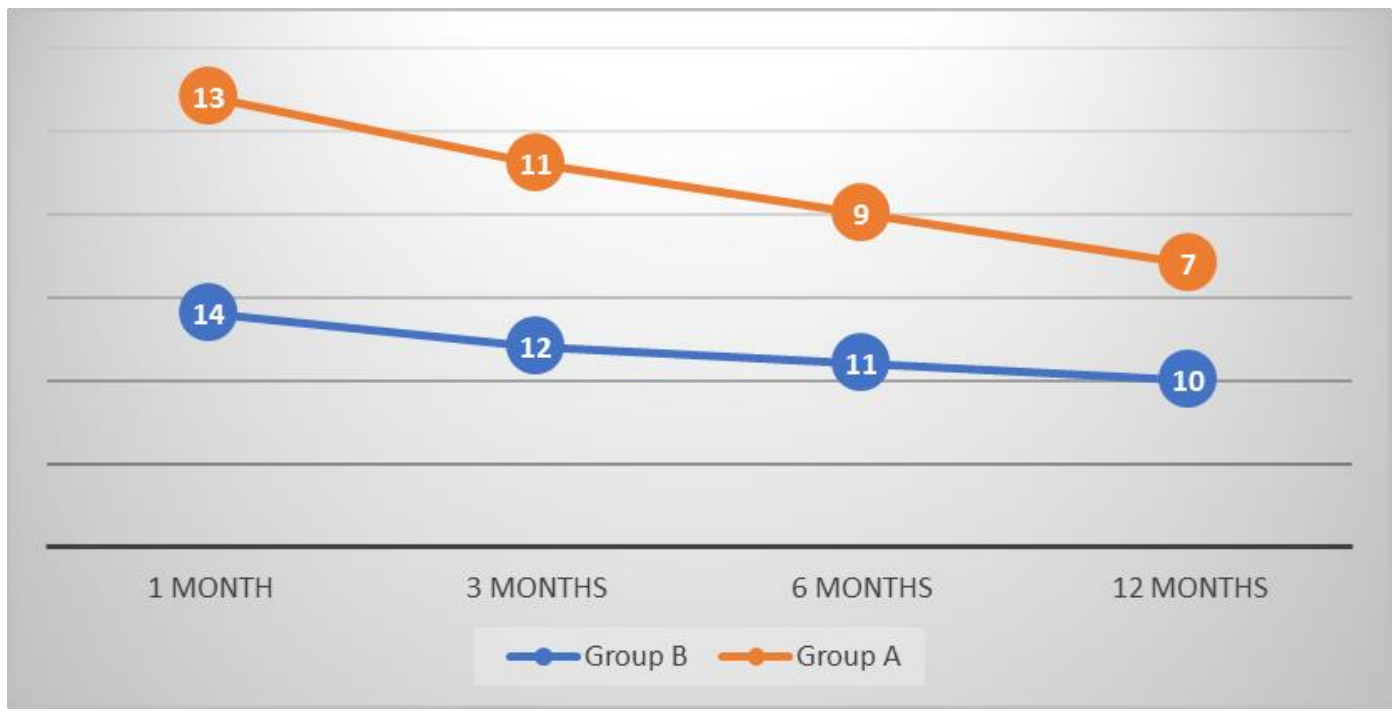

Figure (2): Patency rate

The disappearance of ischemic rest pain and healing of gangrenous and trophic ulcers after minor (toes or transmetatarsal) amputations or debridement was considered as a positive result.
Postoperative improvement of ABI was regarded as an objective indication of improved perfusion of the limb. The difference between the groups was statistically non-significant $(\mathrm{P}=0.07,0.89)$ Table 3).

Table (3): Ankle Brachial Index changes

\begin{tabular}{|c|c|c|c|}
\hline Groups & Group A & Group B & P \\
\hline Preop mean ABI & 0.46 & 0.58 & $>0.85$ \\
\hline Postop mean ABI & 0.90 & 0.89 & $>0.05$ \\
\hline
\end{tabular}

Superficial infection, deep infection and seroma were all confined to bypass group. Other complications were not statistically different in both groups.
There was no significant difference in the mortality rate which was $6.7 \%$ and $13.3 \%$ in group A and B respectively. The Chi-square statistic was 0.3704. The pvalue was 0.54 (Table 4).

Table (4): Post-operative Complications

\begin{tabular}{|c|c|c|c|}
\hline Groups & Group A & Group B & P-value \\
\hline Complications & $6.7 \%$ & $13.3 \%$ & 0.75 \\
\hline Major amputation and mortality & $26.7 \%$ & $13.3 \%$ & 0.16 \\
\hline Superficial infection & $0.0 \%$ & $33.3 \%$ & 0.005 \\
\hline Deep infection & $0.0 \%$ & $6.7 \%$ & 0.0004 \\
\hline Seroma & $0.0 \%$ & $0.0 \%$ & $40.0 \%$ \\
\hline
\end{tabular}




\section{DISCUSSION}

The present study was conducted on $56.7 \%$ males and $43.3 \%$ females. Their ages ranged between 40 years and 80 years. No statistical difference was found regarding age and sex distribution.

The associated comorbidities were IHD and C.V.S. The associated risk factors were D.M., smoking, hypertension, and dyslipidemia. Associated diseases \& risk factors were equally distributed in both groups of intervention.

Symptoms and signs of patients included in this study included rest pain, ischemic ulcers, gangrene of toe, heel or forefoot as shown below. Rest pain was found in 9 patients in group A and 11 in group B. Ischemic Ulcer was found in 6 patients in group A and 5 in group B.

This was in agreement with previous studies (Siracuse et al., 2012, Linnakoski et al., 2013 and Malas et al., 2014).

Regarding interventions, in group A, balloon angioplasty was used without stenting. In group B, autogenous femoropopliteal bypass was used. In endovascular group, in our study, lesions were crossed intraluminal in $93.33 \%$ patients and subintimal in $6.67 \%$.

It was clear that our study had small sample size relatively because of low rate of interventions generally with COVID pandemic and the short period of study.

Mean operation time was calculated for each procedure and exact numbers which was statistically lower in endovascular group.

Mean hospital stay was calculated for each procedure and exact numbers which was statistically lower in endovascular group.

Among our patients, technical success rate after endovascular intervention (group A) reached $93.3 \%$ compared to $86.7 \%$ in femoropopliteal bypass (group B).

We achieved a limb salvage rate of $93.3 \%$ in group A, and $86.7 \%$ in group B and a major amputation rate of $6.7 \%$ in group A, and $13.3 \%$ in group B over 1year follow-up period. No difference was found between both interventions.

Postoperative improvement of ABI was regarded as an objective indication of improved perfusion of the limb. ABI increased from 0.46 before the operation to 0.90 in Group A and from 0.58 to 0.89 in Group B. Both interventions led to significant ABI improvement. The difference between the groups was statistically non-significant.

All our patients in the bypass group received an autogenous graft, and all the patients in the endovascular group treated with balloon angioplasty. Our limb salvage rate was similar in both groups.

The Basil trial compared angioplasty with bypass for patients presenting with severe limb ischemia because of infrainguinal disease. The long-term follow-up showed no significant difference in amputation free survival and overall survival up to 2-year follow-up. However, patients who survived beyond the 2 years did better in the surgical group. The immediate failure rate of angioplasty was as high as $25 \%$, and the re-intervention rate was significantly higher in this group compared with the bypass group (Bradbury et al., 2010). 
In a study by Linnakoski et al. (2013) Polytetrafluoroethylene (PTFE) grafts were dominantly used in $96 \%$ of cases and autogenous vein grafts in $4 \%$ of cases in the bypass group.

TASC II categories were $73.3 \%$ class B in group A and $86.7 \%$ in group B. Category $\mathrm{C}$ was found in $26.7 \%$ of patients in group A and $13.3 \%$ in group B.

In comparison with our results, McQuade et al (2010), Dearing et al. (2011), Malas et al. (2014), and Surowiec et al. (2015), with their studies and follow up for 24-month including TASC A, B, C and $\mathrm{D}$. saphenous and PTFE bypass were included, TASC A and B were dominant than $\mathrm{C}$ and $\mathrm{D}$.

Patency rate at 12 months was higher in group B than in group A $(66.7 \%$ vs. $46.7 \%)$. The result was not significant.

The primary patency by Malas (2014) at 24 months was significantly better for the endovascular group 67\% vs bypass group 49\%. Patency rate was $66 \%$. McQuade et al, (2010) patency rate was 63\%, Dearing et al., (2011) patency rate was 55\%. and Malas et al., (2014) reported $67 \%$ patency rate.

In comparison with our results regarding patency rate of endovascular intervention, Surowiec et al. (2015) performed a retrospective analysis comparing PTA with bypass and reported a similar 2-year primary patency of the endovascular group compared with our study.

The disappearance of ischemic rest pain and healing of gangrenous and trophic ulcers after minor (toes or transmetatarsal) amputations or debridement was considered as a positive result.

\section{Regarding}

Postoperative complications, sinfection, deep infection and seroma were all confined to bypass group. Other complications were not statistically different in both groups. Major amputation was $6.7 \%$ and $13.3 \%$ in group $\mathrm{A}$ and $\mathrm{B}$, respectively. Hematoma or bleeding was found in $26.7 \%$ and $13.3 \%$ in group $\mathrm{A}$ and $\mathrm{B}$, respectively.

There was no significant difference in the mortality rate which was $6.7 \%$ and $13.3 \%$ in group A and B respectively. The result was not significant.

Regarding treatment of choice, it remained largely biased by the treating physician's comfort and experience and not necessarily based on the durability of treatment method. McQuade et al (2010). Conducted a prospective randomized study comparing femoral-popliteal bypass with synthetic grafts to endovascular stenting with expanded PTFE/nitinol selfexpanding stent graft.

This study showed no significant difference in primary and secondary patency at 1-, 2-, 3-, and 4-year follow-up between the two groups.

Open bypass remains the gold standard for revascularization of the lower extremity. This treatment method has been extensively evaluated in several prospective well-designed studies, which have shown it to be effective in long-term limb salvage and improving patients' quality of life. Nevertheless, over the last decade there has been a significant shift in the treatment paradigm with an endovascular first approach on all patients evolving in many centers. Therefore, patients undergoing a bypass graft today have much more advanced disease (Malas et al., 2014). 
Our study has an important limitation as the sample size was small (30 patients), which resulted in reducing the ability of the model to show a statistically significant association of several of the covariates with the outcome variable.

\section{CONCLUSION}

Balloon angioplasty and bypass surgery were safe and effective method for treatment of long SFA lesions. Bypass group showed better patency rates at final follow up. Perioperative mortality and limb salvage were not statistically different in both groups. Superficial infection, deep infection and seroma were all confined to bypass group. Other complications were not statistically different in both groups.

\section{REFERENCES}

1. Bosanquet, D. C., Wright, A. M., White, R. D. and Williams, I. M. (2016): A review of the surgical management of heel pressure ulcers in the $21 \mathrm{st}$ century. International Wound journal, 13(1): 9-16.

\section{Bradbury AW, Adam DJ, Bell J,} Forbes JF, Fowkes FG, Gillespie I and Lanz M. (2010): BASIL trial Participants. Bypass versus Angioplasty in Severe Ischaemia of the Leg (BASIL) trial: An intentionto-treat analysis of amputation-free and overall survival in patients randomized to a bypass surgery-first or a balloon angioplasty-first revascularization strategy. Vasc Surg., 51(5 Suppl):5S-17S.

\section{Dearing DD, Patel KR, Compoginis JM, Kamel MA,}

Weaver FA and Katz SG. (2011): Primary stenting of the superficial femoral and popliteal artery. J Vasc Surg., 50:542-8.

4. Karkos, C. D., Karamanos, D. G., Papadimitriou, D. N., Malkotsis, D. P., Demiropoulos, F. P., Papazoglou, K. O., ... and Gerassimidis, S. (2017): Current therapeutic options in the management of superficial femoral artery occlusive disease. Acta chirurgica Belgica, 107(6):605-615

5. Linnakoski, H., Laurila K, Roth WD, Rossi P, Lavonen P. (2013): "Comparison of above-the-knee prosthetic femoro-popliteal bypass versus percutaneous transluminal angioplasty and stenting for treatment of occlusive superficial femoral artery disease. Scandinavian Journal of Surgery, 102(4): 227-233.

6. Malas, M. B. Kugel $H$ and Schellhammer F. (2014): "Comparison of surgical bypass with angioplasty and stenting of superficial femoral artery disease." Journal of Vascular Surgery 59(1): 129-135.

7. McQuade K, Gable D, Pearl G, Theune B and Black S. (2010): Four-yearrandomized prospective comparison of percutaneous ePTFE/nitinol self-expanding stent graft versus prosthetic femoralpopliteal bypass in the treatment of 
superficial femoral artery occlusive disease. J Vasc Surg., 52:584-90.

8. Norgren, L., Hiatt, W. R., Dormandy, J. A., Nehler, M. R., Harris, K. A. and Fowkes, F. G. R. (2017): Inter-society consensus for the management of peripheral arterial disease (TASC II). Journal of Vascular Surgery, 45(1): S5-S67.

9. Papoian, S. A., Shchegolev, A. A., Radchenko, A. N., Gromov, D. G., Mutaev, M. M., Sazonov, M. I., and Ishevskiĭ, A. G. (2018): Remote results of endovascular treatment for TASC II type C and D lesions of the superficial femoral artery. Angiologiia i sosudistaiakhirurgiia $=$ Angiology and Vascular Surgery, 24(1): 73-78.

10. Pattillo, C. B., Bir, S., Rajaram, V. and Kevil, C. G. (2011): Inorganic nitrite and chronic tissue ischaemia: a novel therapeutic modality for peripheral vascular diseases. Cardiovascular Research, 89(3): 533-541.

11. Siracuse, J. J., Giles, K. A., Pomposelli, F. B., Hamdan, A. D., Wyers, M. C., Chaikof, E. L., ... and Schermerhorn, M. L. (2012): Results for primary bypass versus primary angioplasty/stent for intermittent claudication due to superficial femoral artery occlusive disease. Journal of Vascular Surgery., 55(4): 1001-1007.

12. Surowiec SM, Davies MG, Eberly SW, Rhodes JM, Illig KA, Shortell CK, Gable D, Hohman S, Pearl G and Theune B. (2015): Percutaneous angioplasty and stenting of the superficial femoral artery. J Vasc Surg, 4.(7): 11001112. 
در اسة مقارنة بين التوسيع بالبالون و التوصيل الثرياني

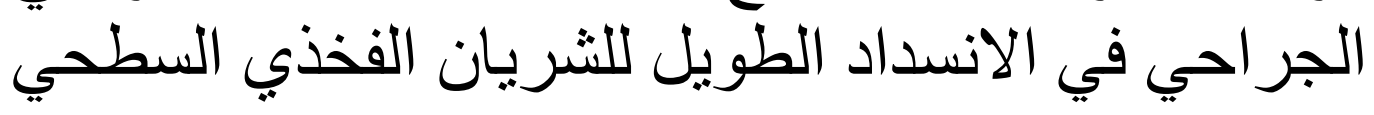
محمد حمدي حسن علي، هاني عبد المؤمن عبد الفتاح، عمر مختار إبراهيم قسم جراحة الأوعية الاموية، كلية الطب، جامعة الأزهـر، القاهرة

E-mail: hamdyvascular@gmail.com

خلقيــة البحــث: يعتبــر القصــور الــدموي الحــرج هـــو المرحلــة الأكثــر تقــدمًا

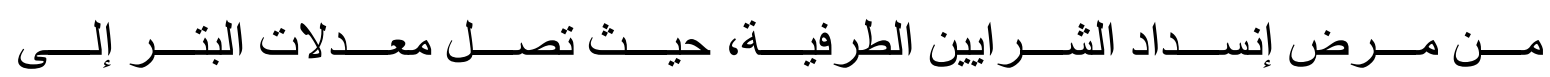
30 و والوفيات تصل إلى 25\% بعد عام واحد.

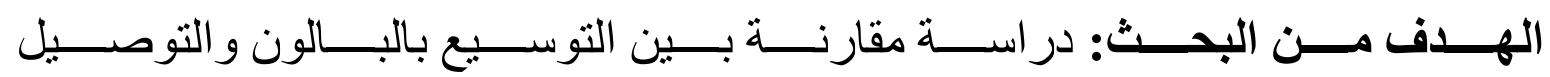
الثرياني الجراحي في الانسداد الطويل للشريان الفذذي السطحي.

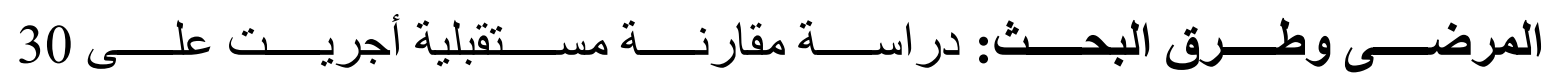

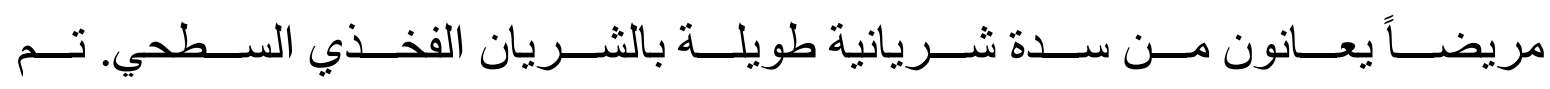

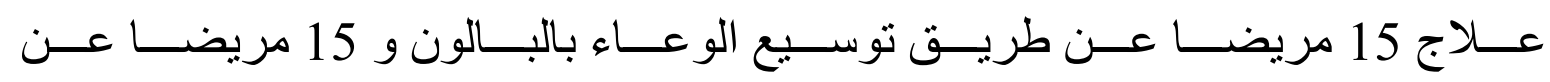
طريق الوصلة الفخذية المأبضية.

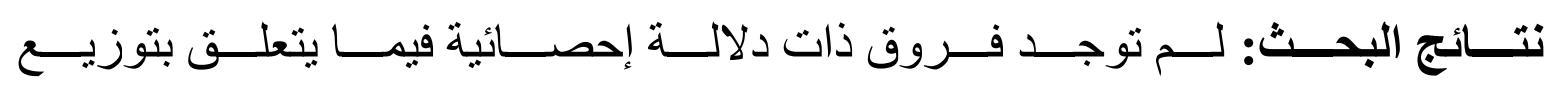

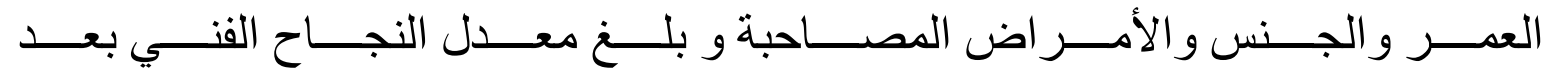

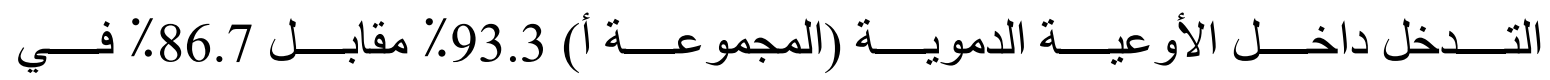

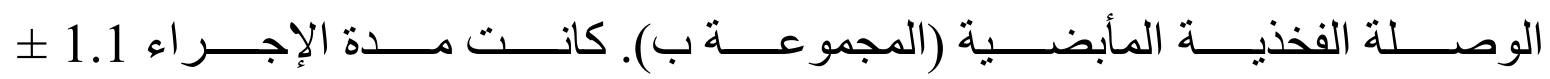

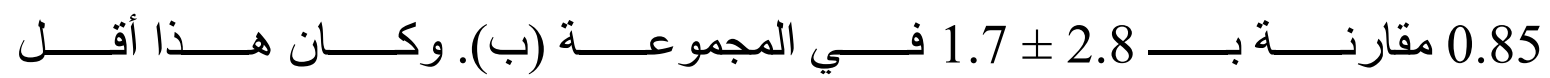

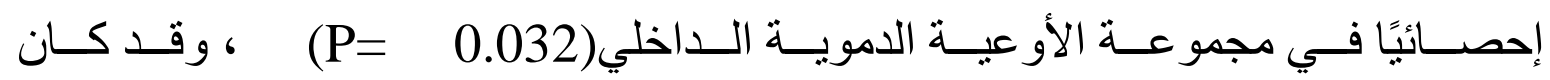

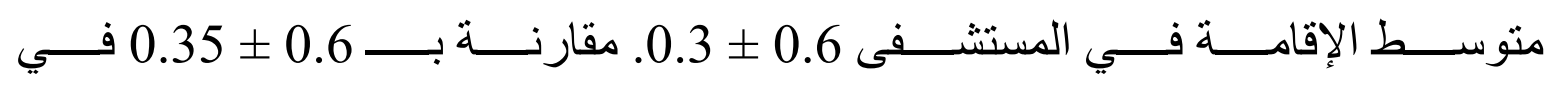

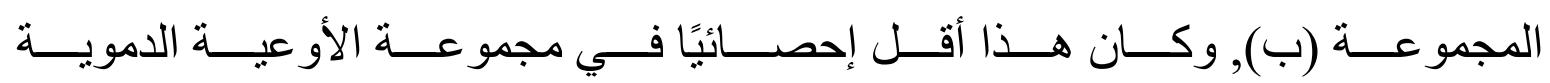

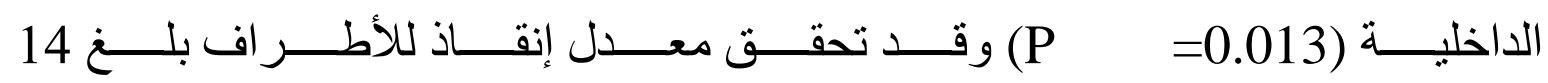




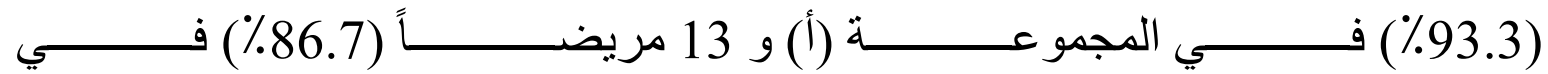

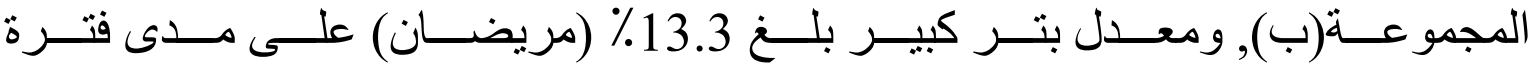

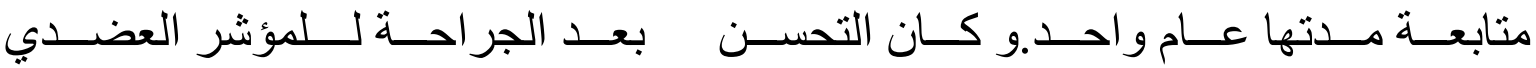

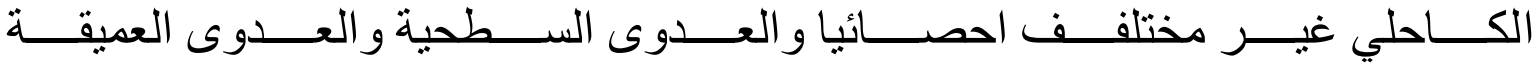

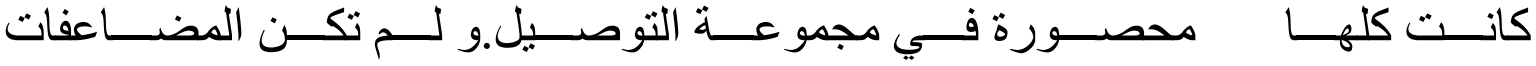

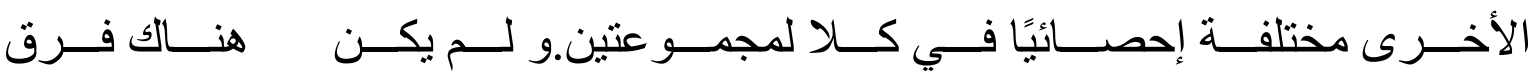

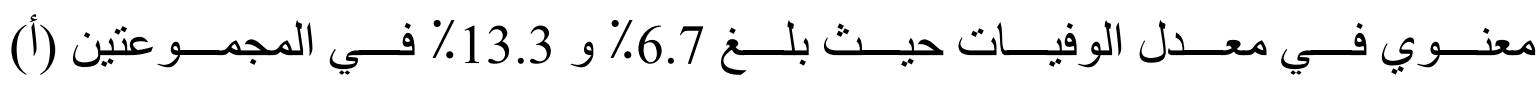
و(ب) علي التوالي.

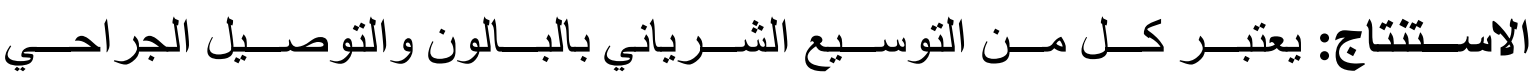

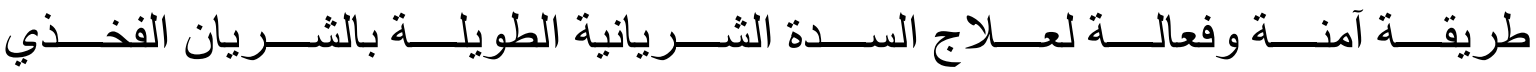

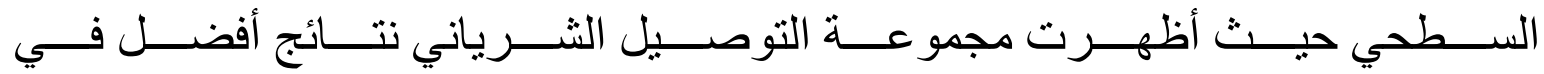

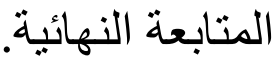

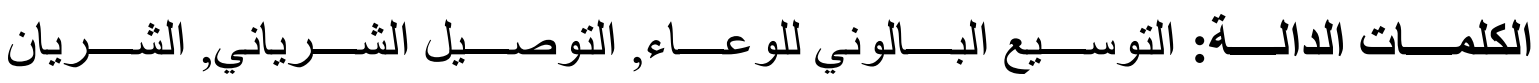
الفخذي. 